\title{
Orange-fleshed Sweet Potato Chips: Processing Effect on Carotenoid Content and Resistant Starch and Sensory Acceptance
}

\section{Thaís Paes Rodrigues dos Santos ${ }^{1^{*}}$}

https://orcid.org/0000-0002-7337-6397

\section{Daiana de Souza Fernandes ${ }^{2}$}

https://orcid.org/0000-0003-2777-3639

\section{Cristine Vanz. Borges ${ }^{3}$}

https://orcid.org/0000-0002-3682-7910

\section{Magali Leonel ${ }^{1}$}

https://orcid.org/0000-0001-7896-2398

\section{Giuseppina Pace Pereira Lima ${ }^{4}$ \\ https://orcid.org/0000-0002-1792-2605}

1São Paulo State University (UNESP), College of Agronomic Science (FCA), Center for Tropical Roots and Starches (CERAT) - Botucatu, São Paulo, Brazil; ${ }^{2}$ Goias Federal University - Samambaia, Goiás, Brazil; ${ }^{3}$ Maria Milza College FAMAM, Governador Mangabeira, Bahia, Brazil; "4São Paulo State University (UNESP), Department of Biochemistry (IBB), Botucatu, São Paulo, Brazil.

Editor-in-Chief: Paulo Vitor Farago

Associate Editor: Ivo Mottin Demiate

Received: 2020.08.10; Accepted: 2021.02.24.

${ }^{*}$ Correspondence: thaispaes.btu@gmail.com; Tel.: +55 1438807158 (T.P.R.S)

\section{HIGHLIGHTS}

- Chips from orange-fleshed sweet potato have a good acceptability.

- Drying process showed retention of carotenoids total content.

- Chips from drying or frying process showed high resistant starch content.

Abstract: There is currently a great demand for industrialized products with functional properties, together with the increase in consumption of roots and sweet potato products. Sweet potatoes have a high content of resistant starch, while only the orange-fleshed roots also have a high content of carotenoids. Due to these, this work aimed to produce orange-fleshed sweet potato chips, by two processes: drying oven and immersion frying. The chips were evaluated for the content of resistant starch and carotenoids in nature and chips sweet potatoes, and evaluations of the physical attributes and sensory analysis of the chips. The drying process retained a greater content of total carotenoids. Fried chips can be considered high resistant starch content, even with a decrease in the content after this processing; they also showed more intense coloring and pleasant texture. There was a statistical difference between the varieties only regarding the content of carotenoids and resistant starch. Thereby, it can be concluded that the chips of both processing have good 
technological and functional qualities, and that the frying process presented best hardness which led to greater acceptability and purchase intention.

Keywords: Beauregard; Clone 1365; color; roasted; fries.

\section{INTRODUCTION}

Sweet potato (Ipomoea batatas (L.) Lam.) is considered a staple food crop, being a rustic plant with wide climatic adaptation, being cultivated in different regions of the world. Sweet potato is the seventh most important food crop in the world and the fifth most important in developing countries. The plant grows best in tropical areas, in most part of these regions, sweet potatoes are an important food, mainly as an energy source. Sweet potatoes are a quite common root in the diet of populations subject to food restriction and are therefore a good way to improve their nutrition [1]. In 2018, the global production of this root reached 91.9 million tons (Mt) and the Brazilian production was 741.2 thousand tons (Kt), highlighting the Asia continent as the one with the highest production (66\%), followed by Africa (28\%) and the Americas (5\%) [2].

Orange-fleshed sweet potato roots can be exploited for their calorie-rich property to alleviate proteinenergy malnutrition but has majorly been recommended for fighting vitamin A deficiency [3]. Orange-fleshed sweet potato roots are rich in provitamin A carotenoids than other sweet potato varieties including cream and white fleshed varieties; the content of the carotenoids vary depending on the intensity of the orange color on the flesh. Even upon cooking, the orange-fleshed sweet potato roots still provide high levels of beta-carotene [4]. Carotenoids is the most potent precursor of vitamin A found in plants. In the human body, beta-carotene is transformed into vitamin $A$, which is essential for the development of vision organs, skin formation and body growth.

Resistant starch is important for its nutritional function, since it acts in a similar way to dietary fibers, optimizing the functioning of the gastrointestinal tract, generating a feeling of satiety, delaying the absorption of monosaccharides and assisting the excretion of fat molecules contained in the fecal bolus [5]. This type of starch is not hydrolyzed by enzymes in the gastrointestinal tract and is fermented in the large intestine. According to Pereira [5], certain food processing, such as baking or drying at high temperatures, increases the level of resistant starch. However, in other processes such as cooking, in water or oil, starches lose their resistance due to the gelatinization process.

During the agricultural production of roots and tubers, part is discarded because it does not reach the commercial standard. A possibility to add value to this material would be the use in the production of chipstype snacks, since this is a simple technology, easy to transfer, low implantation cost, and a growing market product, which can be inserted in programs feed.

Currently, there is a constant search for the consumption of natural foods with functional properties, mainly from fruits and vegetables. Consequently, the global functional food market has expanded dramatically over the past decade and is estimated to grow steadily and reach USD 255.10 billion by 2024 [6]. Numerous studies have concentrated on explaining this relationship between health orientation and functional food consumption [7]. Studies on resistant starch showed that it can be beneficial on the improved insulin sensitivity and glycemic control, and enhanced gut health [8]. Many studies assess the content of antioxidants and carotenoids in orange-fleshed sweet potato products $[9,10]$. However, the evaluation of the maintenance of the quality of these products after processing, regarding the contents of carotenoids and resistant starch are not widespread.

In order to enhance the culture of orange-fleshed sweet potatoes and aiming at technological innovation in the production of sweet potato chips, this work aimed to produce orange-fleshed sweet potato chips of two varieties. As well as, the evaluation of the chips produced regarding the content of carotenoids and resistant starch, physical characteristics, sensory acceptance, and purchase intention. 


\section{MATERIAL AND METHODS}

\section{Material}

The roots of orange sweet potato, variety Beauregard and Clone 1365, were grown on the experimental farm São Manuel - CERAT / UNESP.

\section{Chips processing}

The roots were peeled and washed in running water to remove the adhered dirt. Then, the roots were sliced with an average cut thickness of $2.2 \mathrm{~mm}$, in a slicer (Skymsen Model, Metallurgical Siemsen LTDA., Brusque, SC, Brazil). During the sweet potato processing, to avoid enzymatic browning, ice water was used to immerse the roots and slices, especially during the peeling and cutting stages.

The slices were pre-treated with the bleaching process, being immersed in water at $100{ }^{\circ} \mathrm{C}$ for 6 minutes, then they were removed and immersed in ice water and then drained the excess water. The sweet potato slices were processed in two ways: fried in oil immersion or dried in an air circulation oven.

In the frying process, the slices were fried in soybean oil at $170{ }^{\circ} \mathrm{C}\left( \pm 5^{\circ} \mathrm{C}\right)$ for 2.5 minutes [11]. This process was carried out on electric fryer (Scavone, Porto Alegre, RS, Brazil). After frying the chips were placed in a bowl with absorbent paper for later addition of salt.

In the drying process, the sweet potato slices were distributed on baking sheets covered with aluminum foil and dried in an air circulation oven at $80^{\circ} \mathrm{C}$ for 5 hours, then were added salt.

After deep-frying or drying processing, the orange-fleshed sweet potato chips were allowed to cool to room temperature and stored in plastics, sealed with a sealer (IMAP, Ribeirão Preto, SP, Brazil), to prevent moisture from entering, making the product remain in ideal conditions for consumption.

Both processes were carried out in triplicate for each orange-fleshed sweet potato variety.

\section{Chip flour obtention for analysis of carotenoids and resistant starch}

The orange-fleshed sweet potato in natura and processed chips were dried at $45^{\circ} \mathrm{C}$ and milled in a knife mill (Marconi, Piracicaba, SP, Brazil), to obtain the chip flour to carry out the analyze resistant starch content. For the analysis of the carotenoids total content, the orange-fleshed sweet potato in natura and processed chips were lyophilized.

\section{Total carotenoids}

The total carotenoid content was determined according to Lichtenthaler [12], with modifications. Lyophilized samples $(200 \mathrm{mg})$ were extracted twice with $80 \%$ acetone $(5 \mathrm{~mL})$ by sonication for $30 \mathrm{~min}$. The extracts were combined and centrifuged at 3,800 rpm (10 min). The absorbance of the extracts was measured at 663, 646 and $455 \mathrm{~nm}$, respectively, using a UV-Vis Ultrospec 3000 spectrophotometer (Pharmacia Biotech, Uppsala, Sweden) and expressed in $\mu \mathrm{g} \mathrm{g}^{-1} \mathrm{DW}$ (dry weight). Each sample was analyzed in triplicate.

\section{Resistant starch}

In vitro digestibility was determined in natura and processed chips, following the Englyst method [13], with modifications. Starch $(1 \mathrm{~g})$ was weighed and placed into a centrifuge tube $(50 \mathrm{ml})$ containing phosphate buffer $0.1 \mathrm{M}(20 \mathrm{ml}, \mathrm{pH} 5.2)$ and vortex. After all the centrifuge tubes were equilibrated in a water bath at $37{ }^{\circ} \mathrm{C}$ for $10 \mathrm{~min}$, and $5 \mathrm{ml}$ of enzyme solution [porcine pancreatic $(3.0 \mathrm{~g} / 20 \mathrm{~mL}, \mathrm{P}-1750$, EC 232-468-9, Sigma, St. Louis, MO, USA), amyloglucosidase (140 EU/mL, A-7255, EC 3.2.1.3, Sigma, St. Louis, MO, USA), and invertase (3000 UE/mL, 14504, EC 3.2.1.26, Sigma, St. Louis, MO, USA )] were added, followed by shaking $(150 \mathrm{rpm})$ at $37^{\circ} \mathrm{C}$ in a water bath. At this time and after $120 \mathrm{~min}$, aliquots of hydrolyzed solution $(0.5 \mathrm{ml})$ were taken and placed into a centrifuge tube $(50 \mathrm{ml})$ containing $66 \%$ ethanol $(10 \mathrm{ml})$ and mix well to deactivate the enzyme. Then the centrifuge tube was centrifuged at $3000 \mathrm{~g}$ for $10 \mathrm{~min}$. The glucose content in the supernatant was measured using glucose oxidase/peroxidase reagent kit (Katal/ Interkit - Oxidase/ Peroxidase, ControlLab, Rio de Janeiro, Brasil). $20 \mu \mathrm{L}$ blank, samples, and standard glucose was pipetted in labeled test tubes, after added $2.5 \mathrm{~mL}$ assay reagent. Incubate these test tubes in water bath at $37^{\circ} \mathrm{C}$ for 10 min, after this time leave it cool down to room temperature. Measure absorbance at $505 \mathrm{~nm}$. The percentage of hydrolyzed starch was calculated by multiplying the glucose content with a factor of 0.9 . Each sample was analyzed in triplicate. 


$$
\begin{gathered}
\% \text { Glucose }=\frac{(A t-A b) \times C \times V \times D \times 100}{A s \times w} \\
\% \text { RS }=(\text { TS }-\% \text { Glucose }) \times 0.9
\end{gathered}
$$

Where At is the absorbance of the test solution at $505 \mathrm{~nm}, \mathrm{Ab}$ is the absorbance of the blank solution at $505 \mathrm{~nm}, \mathrm{c}$ is the concentration of the standard solution (in $\mathrm{mg}$ glucose $/ \mathrm{mL}$, offered by the glucose oxidaseperoxidase kit), $\mathrm{V}$ is the total volume of the test solution, $\mathrm{D}$ is a dilution factor, As is the absorbance of the standard solution at $5 \mathrm{~nm}$, and $\mathrm{w}$ is the weight (in $\mathrm{mg}$ ) of sample taken for analysis, which may be corrected for moisture. RS is resistant starch and TS is the total starch content (\%, dry basis) of the sample.

\section{Hardness}

For the determination of the hardness a Texture Analyzer was used (TA.XT. Plus model, Stable Micro Systems, London, UK). The equipment measured the force required for the complete shearing of the chips in a "Warner Braztlzler" cell type, attached to a $50 \mathrm{~kg}$ load cell, probe P75 was used. The parameters used for the analyzes were speed in the pre-test and post-test: $2 \mathrm{~mm} \mathrm{~s}^{-1}$, speed in the test: $2 \mathrm{~mm} \mathrm{~s}^{-1}$, distance covered: $5 \mathrm{~mm}$. The hardness values were expressed in grams force (gf). Six chips were used, from each process and repetition.

\section{Color}

Color determination was performed in a Minolta CR-400 colorimeter (Konica Minolta Sensing, New Jersey, USA). The determination occurred in Hunter's CieLab system, defined by the space $L^{*} a^{*} b^{*}$, with determination of the hue angle and chromaticity. In the CieLab system, $L^{*}$ indicates the luminosity or brightness, varying in a scale from black (0) to white (100); the parameters $\mathrm{a}^{*}$ indicates the variation between the green $(-60)$ and red $(+60)$ pigments and $b^{*}$ the variation between the blue $(-60)$ and yellow $(+60)$ pigments; $h^{\circ}$ indicates the saturation of the color and the $C^{*}$ indicates the intensity of the color itself. The hue angle $\left(h^{\circ}\right)$ and the chromaticity $\left(\mathrm{C}^{*}\right)$ were calculated according to the equations:

$$
\begin{aligned}
& h^{\circ}=\tan ^{-1}\left(b^{*} / a^{*}\right) \\
& C^{*}=\left[\left(a^{*}\right)^{2}+{ }^{*}\left(b^{*}\right)^{2}\right]^{1 / 2}
\end{aligned}
$$

The results were expressed as an average of 2 readings. Six chips were used for each process and repetition.

\section{Sensory acceptance and purchase intention}

Sensory evaluation and purchase intention were carried out at São Paulo State University (UNESP) with 64 untrained panelists, of both genders and adults. The four samples were randomly coded, presented with three assorted digits and differently positioned for each panelist. The panelists evaluated each sweet potato chip individually without comparing with each other and each panelist received water at room temperature to cleanse their palate between samples. For sensory analysis, each consumer evaluated each sample to check the consumer acceptance and opinion, and a hedonic scale of nine points (1, extremely dislike; 5 , neither dislike nor like; 9, extremely like), was used [14]. The attributes evaluated were texture, flavor, and overall appearance. For purchase intention was used the scale of 1 to 5 points (1, certainly would not buy; 3 , maybe would buy / maybe would not buy; 5 , would certainly buy), then the values were transformed into a percentage considering the total of tasters. The project was approved by the Ethics Committee of the Faculty of Medicine of the São Paulo State University, under protocol number CAAE 79842317.4.0000.5411.

\section{Statistical analysis}

The data obtained in the analysis of the orange-flesh sweet potato in natura and processed chips were analyzed by analysis of variance (ANOVA), complemented with Tukey's means comparison test $(<0.05)$, using the SISVAR program (Version 5.7, DEX/UFLA). The sensory analysis data of cheese bread were tested by ANOVA [15]. 


\section{RESULTS AND DISCUSSION}

\section{Total carotenoids and resistant starch contents}

The variety and the thermal processing influenced the content of total carotenoids in sweet potato roots. Roots of the variety Clone 1365 showed higher values of total carotenoids, differentiating statistically from the variety Beauregard. After the drying process there was an increase in the total carotenoid content of $137.4 \%$ for the variety Clone 1365 , and $36.2 \%$, for the Beauregard. This behavior can be attributed to the collapse of the cellular structure caused by thermal processing, improving the extraction capacity of the matrix compounds. However, the frying process induced considerable losses regardless of the variety analyzed, of 30 and $48 \%$ of that compound, of the varieties Clone 1365 and Beauregard, respectively. The high temperature used in the frying process may have led to the isomerization and/or oxidation of the compounds, causing a decrease in the total carotenoid content. In addition, the polarity of carotenoids and oil are similar, which may have led to the migration of compounds to the medium used in this type of processing [16].
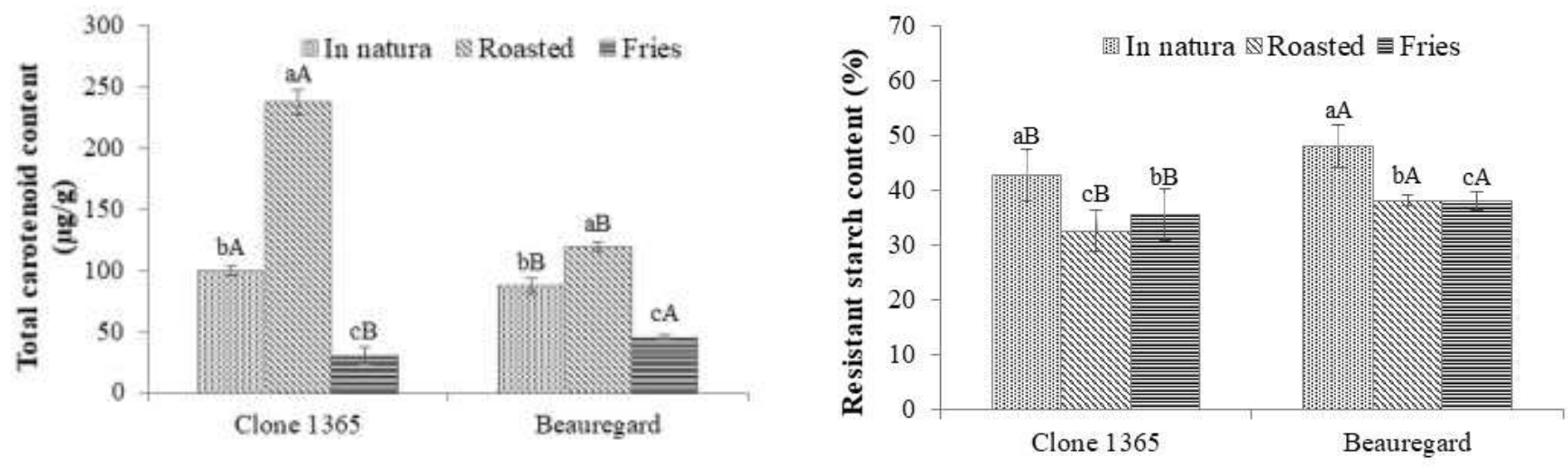

Figure 1. Carotenoids and resistant starch content in orange-flesh sweet potato chips.

Values followed by the same lower-case letter in a column do not differ statistically from each other within the same variety, Tukey's HSD test $(p<0.05)$. Values followed by the same capital letter in a column do not differ statistically between varieties within the same processing, Tukey's HSD test $(p<0.05)$.

The resistant starch contents of the roots of Beauregard and Clone 1365 sweet potato showed a significant difference, the Beauregard showed higher content. Cooking methods significantly affected the resistant starch content in food. Boiling is believed to induce gelatinization, thereby permanently disrupting the amylose-amylopectin structure of the starch complex, thus making it more readily accessible by digestive enzymes [17]. Sweet potato chips showed a significant decrease in resistant starch after the drying and frying processes, from both varieties. Trancoso-Reyes and coauthors [9] found that microwaving and steaming decreased the content of resistant starch significantly. The change can be related to the fact that the crystallinity of sweet potato starch is usually destroyed during heating [18]. The Clone 1365 had lower levels (on average $34.0 \%$ ) independent of the process and showed difference statistically from the variety Beauregard.

\section{Physical analysis}

The types of processing of the chips showed a significant difference in hardness (Table 1). It was more difficult to break the chips produced by drying in the oven than frying by immersion. On the other hand, chips fried seemed more brittle and easily deformed. The result was not surprising, as the chips processed in drying oven were thicker and had a gelatinized starch texture, perhaps due to the bleaching step, carried out before dehydration. This may have occurred because the gelatinized starch in the chips behaves as a barrier, which prevents saturated steam from escaping during drying; thus, few large bubbles are formed on its surface [19]. Among sweet potato varieties, hardness did not show significant difference. 
Table 1. Physical analysis of orange-flesh sweet potato chips roasted and fries.

\begin{tabular}{llccc}
\hline \multirow{2}{*}{ Samples } & Hardness $(\mathrm{gf})$ & \multicolumn{3}{c}{ Color } \\
\cline { 3 - 5 } & & $\mathrm{L}^{*}$ & $\mathrm{a}^{*}$ & $\mathrm{~b}^{*}$ \\
\hline Beauregard - roasted & $36.56 \pm 1.42 \mathrm{aA}$ & $41.62 \pm 1.71 \mathrm{bA}$ & $11.36 \pm 1.72 \mathrm{bB}$ & $24.62 \pm 1.13 \mathrm{bB}$ \\
Beauregard - fries & $17.41 \pm 0.46 \mathrm{bA}$ & $53.09 \pm 2.08 \mathrm{aA}$ & $17.94 \pm 0.75 \mathrm{aB}$ & $44.31 \pm 2.57 \mathrm{aA}$ \\
Clone 1365 - roasted & $45.12 \pm 4.01 \mathrm{aA}$ & $43.77 \pm 1.48 \mathrm{bA}$ & $15.67 \pm 0.28 \mathrm{bA}$ & $28.90 \pm 1.60 \mathrm{bA}$ \\
Clone 1365 - fries & $10.63 \pm 0.62 \mathrm{bA}$ & $52.58 \pm 1.77 \mathrm{aA}$ & $20.11 \pm 0.23 \mathrm{aA}$ & $46.52 \pm 1.85 \mathrm{aA}$ \\
\hline
\end{tabular}

Values followed by the same lower-case letter in a column do not differ statistically from each other between processing within the same variety, Tukey's HSD test $(p<0.05)$. Values followed by the same capital letter in a column do not differ statistically between varieties within the same processing, Tukey's HSD test $(p<0.05)$.

The frying process showed a higher $b^{*}$ value (blue-yellow chromaticity) and $a^{*}$ value (green-red chromaticity) in the two varieties, differing from drying in an air circulation oven. Regarding variety, Clone 1365 showed higher values, different statistically from the Beauregard (Table 1), except from $b^{*}$ value of the fries processing. For the luminosity, the frying process presented chips with superior luminosity than those drying in an oven, differing statistically. However, there was no statistical difference between varieties. Thus, the frying process presented chips with a more intense color for the reddish orange, which is a more desirable quality for chips, according to consumer preference (Figure 2).

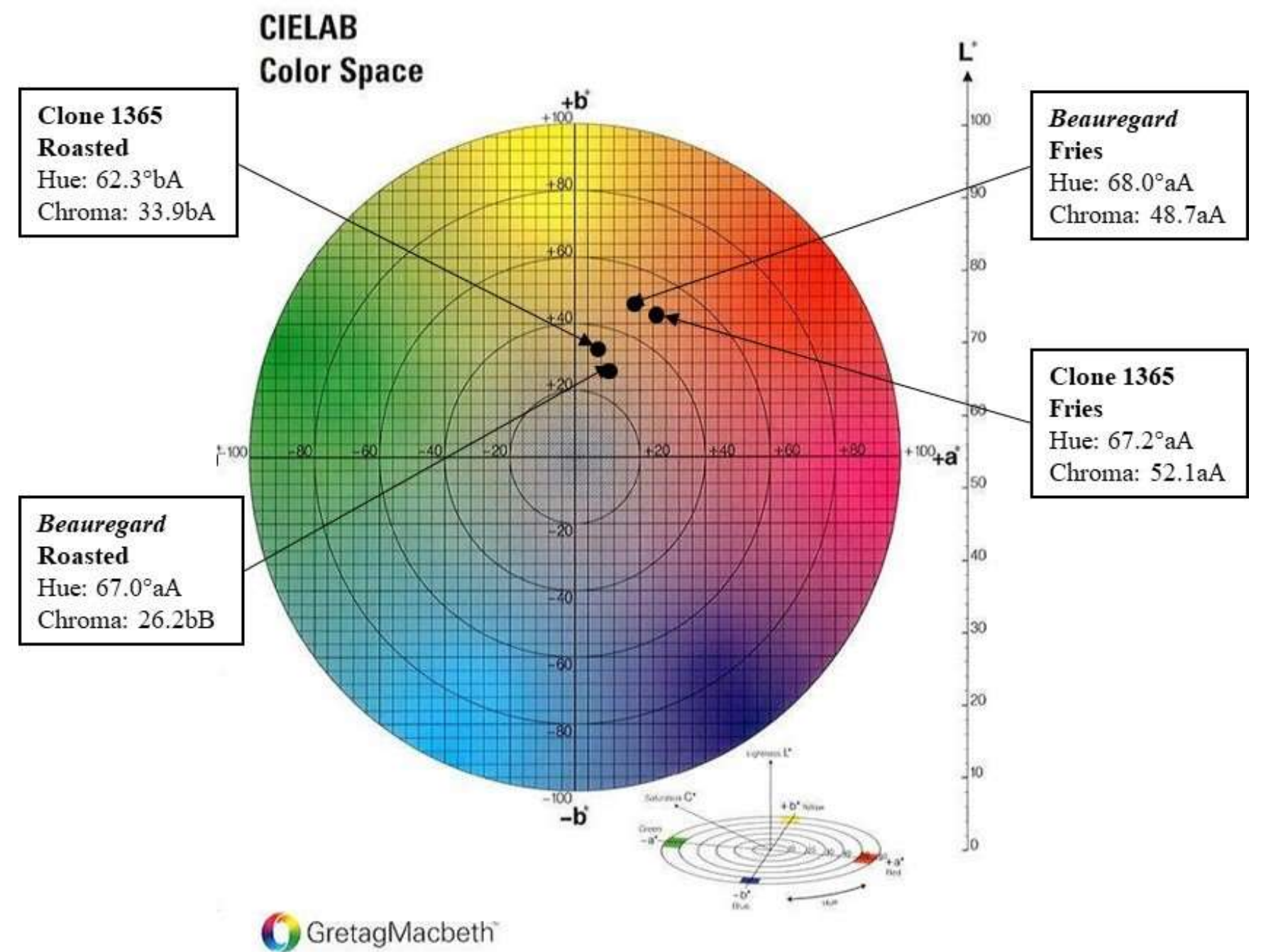

Figure 2. Color diagram with results of the analysis of the orange-fleshed sweet potato chips.

Values followed by the same lower-case letter in a column do not differ statistically from each other between processing within the same variety, Tukey's HSD test $(p<0.05)$. Values followed by the same capital letter in a column do not differ statistically between varieties within the same processing, Tukey's HSD test $(p<0.05)$.

\section{Acceptance test and purchase intention}

Among the treatments, the chips with the best acceptance for both the Beauregard variety (6.84) and for Clone 1365 (6.95) were obtained by the frying process, varying significantly in all parameters of the oven 
drying process (4.31 and 4.17 for the Beauregard variety and Clone 1365, respectively). While the preference among varieties, both Clone 1365 and Beauregard variety showed greater acceptance. Among the processes, the chips with the best acceptance of the chips' texture were obtained by the frying process and showing no preference as to the variety, 6.58 and 6.78 for the Beauregard variety and Clone 1365, respectively. The grades for the texture attribute in the drying in the oven were the lowest, which corroborates the results of the hardness analysis and can confirm the hypothesis that there was a hardening of the gelatinized starch, due to the previous treatment (3.83 and 3.66 for the Beauregard variety and Clone 1365, respectively).
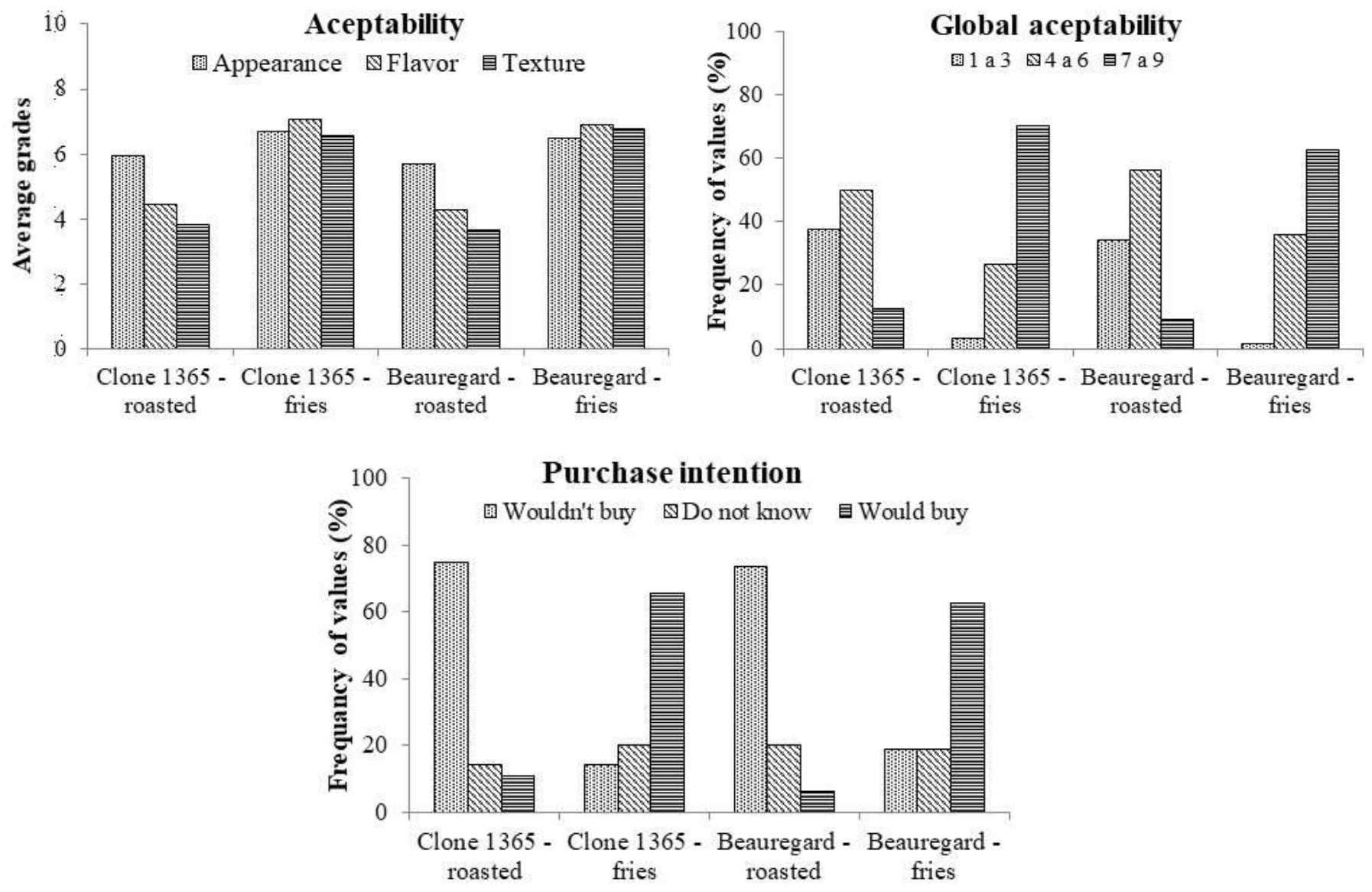

Figure 3. Acceptability test and purchase intention of orange-flesh sweet potato chips.

When evaluating the purchase intention, the tasters also showed preference for the chips produced by the immersion frying process, regardless of the orange-fleshed sweet potato variety (3.8 for both varieties). The texture of the chips was the attribute that most influenced the purchase intention and can be considered a key attribute for the development of these products.

\section{CONCLUSION}

The chips produced by drying in the oven had a higher content of carotenoids, varying according to the variety used. The chips from orange-fleshed sweet potato showed higher resistant starch content, even with reduction after both processing. Orange-fleshed sweet potato chips processed by immersion frying obtained high purchase intent and better sensory acceptance. As for sensory analysis, the processes showed similarly only in appearance. The tasters did not show preference regarding the variety, only regarding the type of processing, indicating that the frying presents good acceptability. While the drying process needs adjustments. It can be concluded that the production of orange-fleshed sweet potato chips has a high commercialization potential, in addition to being a viable way of adding value to the in natura material through simple processing.

Funding: This research received no external funding.

Acknowledgments: The authors thank the Center for Tropical Roots and Starches (CERAT/UNESP) for the availability of materials and laboratories used in this study.

Conflicts of Interest: The authors declare no conflict of interest. 


\section{REFERENCES}

1. Silva JBC da, Melo WF de, Buso JA, Nutti MR, Carvalho PGB de, Carvalho JLV de, Nunes MUC, Farias A Beauregard: cultivar testada e indicada de batata-doce. Brasília, DF: Embrapa Hortaliças; 2010.

2. FAO - Food and Agriculture Organization of the United Nations. FAOSTAT: Production-Crops. 2018. [cited 2020 Apr]. Available in: <http://faostat3.fao.org/home/E>.

3. Honi B, Mukisa IM, Mongi RJ. Proximate composition, provitamin A retention, and shelf life of extruded orangefleshed sweet potato and bambara groundnut-based snacks. J. Food Process. Preserv. 2017;42:1-8.

4. Vimala B, Nambisan B, Hariprakash B. Retention of carotenoids in orange-fleshed sweet potato during processing. J Food Sci Technol. 2011;48:520-4.

5. Pereira KD. Resistant starch, the latest generation of energy control and healthy digestion. Ciênc. Tecnol. Aliment. 2007;27:88-92.

6. Barauskaite, D, Gineikiene, J, Fennis, BM, Auruskeviciene, V, Yamaguchi, M, Kondo, N. Eating healthy to impress: How conspicuous consumption, perceived selfcontrol motivation, and descriptive normative influence determine functional food choices. Appetite 2018;131:59-67.

7. Kaur, N., \& Singh, D. P. (2017). Deciphering the consumer behaviour facets of functional foods: A literature review. Appetite,112,167-87.

8. Raatz, SK, Idso, L, Johnson, LK, Jackson, MI, Combs Jr, GF. Resistant starch analysis of commonly consumed potatoes: Content varies by cooking method and service temperature but not by variety. Food Chem. 2016;208:297-300.

9. Trancoso-Reyes N, Ochoa-Martinez LA, Bello-Perez LA, Morales-Castro J, Estevez Santiago R, Olmedilla-Alonso B. Effect of pre-treatment on physicochemical and structural properties, and the bioaccessibility of beta-carotene in sweet potato flour. Food Chem. 2016;200:199-205.

10. Owade, OO, Abong, GO, Okoth, MW. Production, Utilization and Nutritional benefits of Orange Fleshed Sweetpotato (OFSP) Puree Bread: A Review. Curr. Res. Nutr. Food Sci. 2018;6:644-55.

11. Choe E, Min DB. Chemistry of deep-fat frying oils. J. Food Sci. 2007;72:77-86.

12. Lichtenthaler HK. Chlorophylls and carotenoids: Pigments of photosynthetic biomembranes. In: Packer L, Douce R, editors. Meth. Enzymol. 1987;148:350-82.

13. Englyst HN, Kingman SM, Cummings JH. Classification and measurement of nutritionally important starch fraction. Eur. J. Clin. Nutr. 1992;46:S33-S50.

14. Berwig KP, Marques DR, Silva DMB, Mendes MP, Raniero GZ, Monteiro CCF, Monteiro ARG. Texture on extruded snack: correlation between instrumental and sensory analysis. Chem. Eng. Transactions. 2017;57:1723-8.

15. Stone, H, Sidel, J L. (2004). Mensurement. In: Stone, H., Sidel, J. L. (Eds.) Sensory evaluation practices (pp. 6997). San Diego: Academic Press.

16. Borges, CV, Minatel, IO, Amorim, EP, Belin, MAF, Gomez-Gomez, HA, Correa, CR, Lima, GPP. Ripening and cooking processes influence the carotenoid content in bananas and plantains (Musa app.). Food Res. Int. 2019;124:129-36.

17. Bahado-Singh PS, Riley CK, Wheatley AO, Lowe HIC. Relationship between processing method and the glycemic indices of ten sweet potato (Ipomoea batatas) varieties commonly consumed in Jamaica. J. Nutr. Metab. $2011 ; 2011: 1-6$.

18. Szepes A, Hasznos-Nezdei M, Kovacs J, Funke Z, Ulrich J, Szabo-Revesz P. Microwave processing of natural biopolymers-studies on the properties of different starches. Int. J. Pharm. 2005;302:166-71.

19. Kawas ML, Moreira RG. Effects of degree of starch gelatinization on quality attributes of fried tortilla chips during frying. J. Food Sci. 2001;66:195-210.

(C) 2021 by the authors. Submitted for possible open access publication under the terms and conditions of the Creative Commons Attribution (CC BY NC) license (https://creativecommons.org/licenses/by-nc/4.0/). 